\title{
Evaluation of a Mental Health Information and Referral Service
}

\author{
Doris A. Berlin, M.D., M.P.H.
}

ABSTRACT: This paper reports on the application of a method for evaluating public health programs to a mental health intake and referral service of a suburban county of a midwestern state. The method involves measurement of program objectives and subobjectives in order to ascertain program effectiveness. Evaluation provided useful information with regard to the agencies using the service, the flow of patients through the program, and the subsequent flow, through a hospital outpatient clinic, of a majority of patients referred for diagnosis or treatment. The effect of treatment was not included in the evaluation.

\section{INTRODUCTION}

In mental health as in public health, there have been nany attempts to show the worth of various programs. A number of difficulties beset these evaluations, but particularly evident has been the lack of a general procedure or methodology.

Recently Deniston, Rosenstock, \& Getting (1968) presented a general model for program evaluation. Their concepts and methodology are applicable to the evaluation of any health program, they believe. This paper reports on the use of their method in evaluating a mental health information and referral service administered by a midwestern county Mental Health Services Board. Called the Central Intake and Referral Service (I \& R), this program need not be identified further; it was begun in 1965 in response to a community need for a place to call for mental health information. Soon it expanded to provide intake and referral services also.

\section{The Model}

In the model applied here, the program administrator must state his program objectives and specify a series of subobjectives or necessary conditions for attaining program objectives as well as the activities

When this paper was written, Dr. Berlin was Research Associate in Public Health Administration, School of Public Health, The University of Michigan, Ann Arbor, Michigan. She is now Director of Professional Education, Toledo State Hospital, and Clinical Associate in Psychiatry, Medical College of Ohio, Toledo, Ohio 43606. This investigation was supported by the Public Health Service Reserach Grant No. CH ooo44 from the Division of Community Health Seroices. 
designed to attain the subobjectives. The procedure then involves measuring the extent to which objectives are attained as a consequence of program activity. This is defined as program effectiveness.

In the ideal situation, a plan for program evaluation is developed when the program itself is initiated. Measurable objectives and subobjectives can then be chosen and recording systems designed to provide needed data. This is not always possible, of course; in the present instance, evaluation was not requested until the program had been in operation nearly two years. The limitations inherent in a retrospective study with objectives and subobjectives not explicitly specified until after a program has operated for some time, and with statistics limited to those deemed helpful for program operation rather than evaluation, will be apparent in this paper.

\section{The Program}

The Intake and Referral office was located centrally in the County. Its services were available to any county resident, those seeking mental health care on their own initiative or those referred to I \& $R$ by community agencies such as the Welfare Department, or various family agencies. Callers were asked to come to the I \& R Service office for a detailed interview with the social worker, who then arranged for the client to be seen for needed care elsewhere. A copy of the client's history and worker's recommendations was forwarded to the treatment agency or institution, where the first interview was usually with a psychiatrist for diagnosis; this ordinarily completed the intake process.

Because of some criticism of the service by community agencies, the Director of the Mental Health Services Board asked that an evaluative study be made.

\section{APPLICATION OF THE MODEL}

Since evaluation requires, first, an explicit statement of program objectives and since this had never been formally done, the program director had to construct it retrospectively. It was as follows: County residents who apply to the $I \& R$ Service will receive prompt, appropriate service for their mental health condition at an accessible and appropriate place.

The program director also had to list program subobjectives which, according to Deniston et al., are changes in the mental or physical conditions of target populations which the program activities intend to bring about. Five subobjectives were given:

1. Referring agencies and potential clients must know of the I \& $\mathrm{R}$ Service.

2. They must believe the $I \& R$ program will help them.

3. Those people who call for service must come and receive an intake interview at the $I \& R$ office within a reasonably short time.

4. Each client must receive a prompt recommendation and appointment from the $I \& R$ social worker with regard to where and when he should go for appropriate services.

5. Clients must keep their appointment at the agency or clinic to which they are referred for service. 
As indicated previously, once objectives and subobjectives have been determined, the model requires ascertaining the extent of their attainment. Information is collected at various points in the operation of the program, giving data concerning both the activities of the program and the degree to which these achieve various subobjectives.

\section{METHOD OF EVALUATION}

In evaluating the program discussed here, the year 1966 was chosen for study. In this period, the social worker interviewed 410 patients. She referred them to various places: $17 \%$ to hospitals for inpatient care, $60 \%$ to a general hospital mental health clinic, and the remaining $23 \%$ to a variety of places such as social agencies, private physicians, etc.

Records of the I \& R office were first surveyed. No records had been made of people calling for an appointment but not appearing for interview. Neither had clients been followed to see if they kept their appointments at the place to which they were referred. An early result of this evaluative study was the development of a new record keeping system to overcome these gaps.

Since there were no follow-tup data at the I \& $\mathrm{R}$ office and since interviews with patients were not feasible, it was fortunate that records of the patients sent to the general hospital mental health clinic were made available. Despite limitations, gaps, and inconsistencies, these records provided much valuable information and are the basis of most of the statistics reported here.

The concept behind the use of records of a second agency for the evaluation of the program of another agency involves two considerations. The first concerns the use of different definitions for objectives of the program for its operation and for evaluation. Thus, when the program was set up, "appropriate place" referred to that selected by the social worker, based on her perception of the patient's needs, the institutions available for referral, the services they provided, and their relative accessibility. Her perception of the patient's needs was not expected to be in terms of specific treatments but rather of broad categories, such as diagnostic appraisal, inpatient care, or outpatient care. In the evaluation of appropriateness of referral, however, the agreement of the psychiatrist at the second agency with the social worker was considered the proper criterion. A referral was classed as inappropriate when the doctor sent the patient elsewhere for therapy.

The second consideration involves the difficulty in demarcating clear-cut lines of responsibility between overlapping programs. In this program, the social worker's role was to choose a treatment agency and encourage the patient to go there. It was then up to the patient to go and to follow through on the services offered at the place of referral. Although the provision of diagnostic and therapeutic services was clearly the obligation of the second agen$\mathrm{cy}$, the response of clients to the Intake and Referral Service, it was felt, would clearly affect patients' following through on recommendations made at the clinic. The community Mental Health Services Board, it should be noted, operated both the Intake \& Referral Service and the hospital clinic. 
Hence, the major part of this evaluation study was spent in surveying the case records, at the general hospital mental health clinic, of the $60 \%$ of the I \& $\mathrm{R}$ cases sent there. It should be emphasized that these were not viewed in respect to the operations or effectiveness of the mental health clinic but rather for any light they could shed on the effectiveness or ineffectiveness of the I \& $R$ program itself.

It was possible also to interview a number of case workers in some of the referring agencies. An attempt was made thereby to ascertain the usefulness of the I \& R Service to these agencies.

To summarize, data available provided partial measures of subobjectives $I$ and 2 , but none for subobjective 3 . With regard to 4 , data were available only on the interval between social work intake and psychiatric assessment. Knowledge of the degree of achievement of subobjective 5 and the program objective for $60 \%$ of all I \& R clients seen in 1966 was possible.

\section{FINDINGS}

Subobjectives 1 and 2: Knowledge of, and Attitudes Toward, the I \& $R$ Service by Referring Agencies

A brief questionnaire was used to interview all 22 social workers in 2 family service agencies; a sample of 16 workers in the County Welfare Department, including 5 supervisors; and 2 probation officers of the Justice Court of the County. These agencies accounted for half of the I \& $R$ case load sent to the General Hospital Mental Health Clinic.

Of the 40 caseworkers, 4 did not know of the Intake and Referral Service. An additional 3 had not used it and 5 were not sure. Sixteen of the 28 who had used the service rated the program as "good," 7 as "fair," and 5, "poor." Treatment of clients by I \& R personnel was rated "good" by all caseworkers who used the service but one-fifth commented that service was slow. Many caseworkers had, on occasion, bypassed the I \& R Service by sending people directly to treatment facilities. Thirteen of them felt it was more helpful to send clients to the I \& R office; 13 felt it less helpful, and 2 saw no difference.

All referring agencies reported a lack of "feedback" concerning whether a client had actually appeared at I \& $\mathrm{R}$ and where he had been sent for treatment.

Caseworkers untrained in psychiatric social work or uninformed of community resources for treatment valued the program, especially if time lags and lack of "feedback" could be eliminated. Trained and informed workers considered it unnecessary and perhaps harmful to subject a troubled person to another interview at $I \& R$ before seeing a physician at a third place.

Subobjective 3: Promptness of Intake Interview at the $I$ \& $R$ Office

As indicated earlier, no data on attainment of this subobjective were available. 


\section{Subobjective 4: Time Interval Between Social Work Inter-} view at $I \& R$ and Psychiatric Interview at the Clinic

To interpret the data on subobjectives 4 and 5 as well as the program objective itself, it was necessary to introduce a comparison group who attended the mental health clinic of the hospital but who did not come through the I \& R Service. This permitted estimation of the extent to which attainment of objectives was due to program activities rather than to other factors. To develop this comparison group, 160 patient names were chosen at random from the master list of the clinic's 1966 case load (after removing those cases that came from the I \& R Service, which made up about one-third of the case load). The charts of these people were then studied for information similar to that obtained for the study group. In short, the 1966 case load of the clinic was divided into two groups: 1 ) the total cases coming from I \& $R$, and 2) a probability sample of other patients. The latter group is hereafter called the "comparison group."

It may be seen from Table 1 that for those patients seen by a physician, the interval between intake and interview was greater for the I \& $R$ group than for the comparison group. More than half of the comparison group had their medical appointment within a week of their intake visit and over $97 \%$ saw the physician within a month. For the I \& $\mathrm{R}$ group, only $13 \%$ saw the physician within a week and about $60 \%$ within a month. More than $20 \%$ of the I \& R group waited over two months between intake interview and seeing the doctor. Thus, using the comparison group as the standard, it would appear that the I \& $\mathrm{R}$ Service was not attaining its subobjective of providing prompt referrals.

\section{TABLE I}

Per cent of patients seen within various time intervals between social work interview and physician's examination

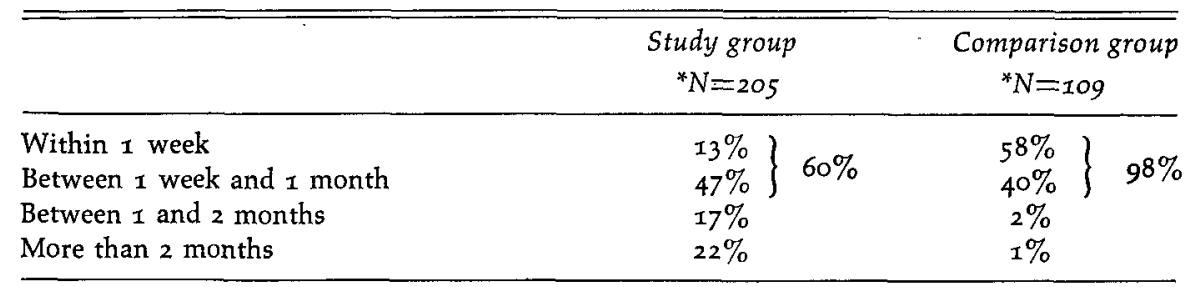

* Excluding patients who never appeared for physician interview or for whom information was not available.

Subobjective 5: Per Cent of Patients Who Appeared for Psychiatric Interview at the Clinic

This was measured by determining the proportion of patients who actually saw the doctor. The figures for the I \& $R$ group and the comparison group are about the same. Eighty-four per cent of the I \& R group and $85 \%$ of the comparison group kept this appointment, a surprising result 
in view of the delays in referral. It might have been expected that, the longer the interval between intake and visit to the physician, the fewer clients would keep their appointments. While no available information explains this finding, it may have been related to a longer social work interview for I \& $R$ cases than for those cases getting their casework interview at the hospital clinic. This is suggested by the more detailed histories in the I \& $R$ case records. Longer interviews may have facilitated better patient rapport, which, in turn, may have helped such patients keep even a long-delayed appointment with a psychiatrist.

\section{The Program Objective}

It will be remembered that the objective was concerned with patients' getting appropriate services in an accessible and appropriate place as quickly as possible. These will be discussed separately below.

Accessibility of service. In terms of the proximity of the applicant's residence to the hospital clinic, it was found that similar percentages of patients, $71 \%$ and $75 \%$, respectively, from the comparison and study groups, came from three catchment areas of the county's five. These are the more densely populated areas and are relatively close to the clinic. Since the county is about 30 miles square, few persons had to travel more than an hour to get help. Accessibility relates to availability of public transportation as well as to time and distance, of course, but these factors were not investigated in this study.

Appropriateness of referral. The question of the appropriateness of the referral to the hospital clinic from the I \& R Service arises from the fact that $15 \%$ of the cases were sent elsewhere for therapy by the doctors. Two factors interfere markedly with any definitive assessment, however: one is the long time interval between I \& $R$ and clinic visits, during which the patient's condition may have changed considerably; if for the worse, hospitalization may well have been indicated at the time of the doctor's assessment but not when the patient saw the social worker. Here, referral would certainly be considered slow, but not necessarily inappropriate. The second intervening variable is the advent of psychiatric insurance coverage for many of the I \& $R$ clients during the period studied; this accounted for referral of some cases to private care.

In other words, except for geographic accessibility, it is difficult to determine to what extent I \& R clients were referred to an "appropriate place." The fact that nearly the same percentage of patients from the comparison group was referred elsewhere by clinic doctors (see Table 2) suggests that going through the Intake and Referral Service neither improved nor decreased one's chances of getting to the right place for one's mental health needs.

Promptness of service. Promptness of service was discussed under subobjective 4. Intake and Referral patients clearly did not see the doctor as quickly as those sent directly to the clinic. 
Receipt of "appropriate service." Of the 208 patients in the stady group and 131 in the comparison group who saw the physician, follow-up records were adequate on 202 and 129, respectively. Table 2 shows the major recommended outcomes of this interview.

TABLE 2

Outcome of doctor's assessment

\begin{tabular}{|c|c|c|c|c|}
\hline & \multicolumn{2}{|c|}{$\begin{array}{c}\text { Study group } \\
N=202\end{array}$} & \multicolumn{2}{|c|}{$\begin{array}{c}\text { Comparison group } \\
\quad N=129\end{array}$} \\
\hline & $\mathrm{N}$ & $\%$ & $\mathrm{~N}$ & $\%$ \\
\hline Sent elsewhere for therapy & 30 & 15 & 18 & 14 \\
\hline Diagnosis alone considered sufficient & 25 & 12 & $I$ & 1 \\
\hline Treatment at clinic recommended & 147 & 73 & IIO & 85 \\
\hline $\begin{array}{l}\text { Total number for whom diagnostic or } \\
\text { treatment services were recommended } \\
\text { at clinic }\end{array}$ & 172 & 85 & III & 86 \\
\hline
\end{tabular}

Leaving out those cases sent elsewhere for therapy, there remain 172 and III cases, respectively, in the study and comparison groups. Table 3 shows what happened to those patients.

\section{TABLE 3}

Receipt of "appropriate service" in clinic by patients for whom such service was recommended

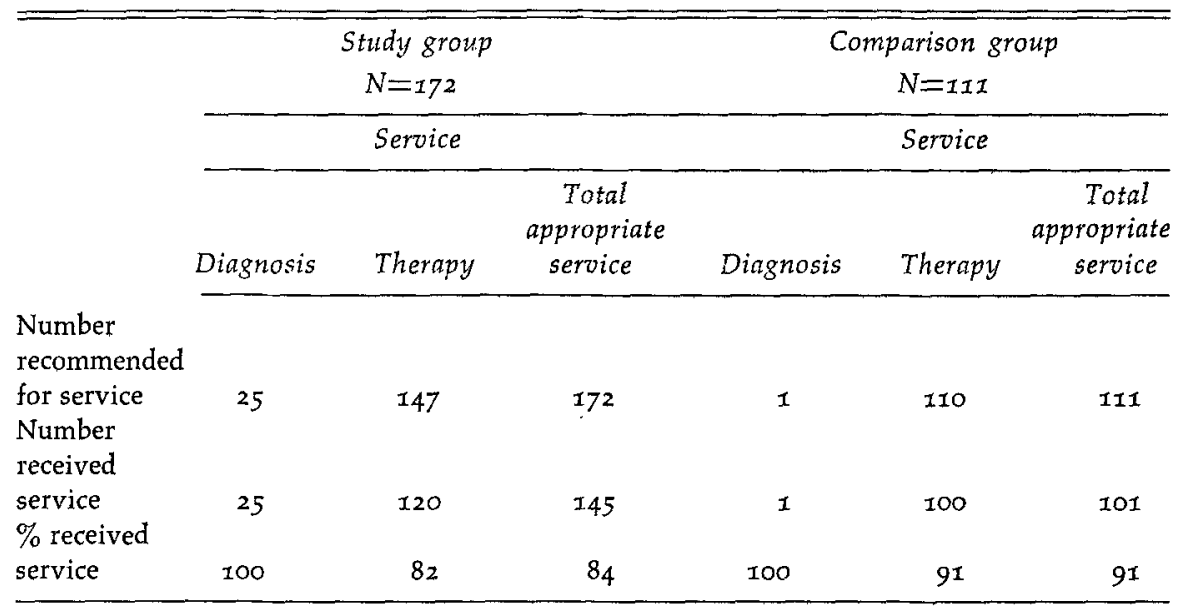

As indicated earlier, the category of "appropriate service" may refer to the diagnostic examination alone when, in the opinion of the psychiatrist, it was sufficient. Diagnosis may have been the sole purpose of the original referral; a patient, for example, may have been sent by the Welfare Depart- 
ment for a diagnostic report in order to determine whether his mental disability justified a pension. The higher percentage of cases in the study group $(15 \%)$ as compared to the comparison group ( $1 \%$ ) for whom diagnosis alone was the only service given may reflect the higher per cent of cases referred from the Welfare Department in the study group.

Other grounds for the psychiatrist's decision that diagnosis alone was sufficient may be that the patient's condition did not require therapy, or that the patient was not sufficiently motivated to benefit from therapy.

With regard to treatment, of the 147 and the 110 for whom some form of therapy at the clinic was recommended, $82 \%$ of the study group and $91 \%$ of the comparison group came for at least one therapy visit. This difference is statistically significant at the .05 level. Similarly, the difference between the $84 \%$ of the Study Group and $91 \%$ of the Comparison Group who received "appropriate service" at the hospital clinic is significant at the same level. Whether the $9 \%$ and $7 \%$ differences are important for program purposes depends on the judgment of the program director.

It may be noted that the percentage of patients receiving "appropriate service" $^{\prime \prime}$ is a rather high figure for both groups. This is probably due to these data being based upon the number of patients seeing the psychiatrist for whom the physician considered such services indicated. It does not include those sent elsewhere for therapy; neither does it include those who never showed up at the clinic for the doctor's examination.

\section{Comparability of the $I \mathcal{E} R$ and Comparison Groups}

The findings presented on subobjectives 4 and 5 and the program objective demonstrate that there is considerable delay in obtaining treatment for patients going through the I \& R Service and that going through the service reduces the probability of obtaining treatment. This interpretation, however, depends upon the comparability of the study group and the comparison group. It is possible that there are systematic differences between the two groups: for example, that more seriously ill people, for one reason or another, go to the I \& R Service; or that the groups differ significantly in age, sex, marital state, etc.

To test whether such systematic differences did exist, a series of comparisons was undertaken. These showed that the study and comparison groups did not vary beyond the $5 \%$ level of chance expectation with regard to age, sex, education, marital status and diagnosis.

Referral sources. Table 4 lists the places from which the 172 and 111 patients in Table 3 had been sent-either to the I \& R Service for those in the study group, or to the hospital clinic directly, in the case of the comparison group. Eleven \% were self-referred in both. The social service agencies, Welfare Department, and the courts made up $48 \%$ of the referral sources for the study group as contrasted to $7 \%$ of the comparison group. More than $1 \frac{1 / 2}{2}$ times as many patients of the comparison group were referred by friends or 
relatives (18\%) as compared to the study group (11\%). Physicians (not including psychiatrists) referred $23 \%$ of the clinic group as contrasted to $5 \%$ of the I \& R group.

It was considered possible that these differences in referral source might well have affected the percentages receiving treatment or "appropriate service." Accordingly, the outcome with regard to attaining appropriate service was computed for each category of referral source (Table 4).

\section{TABLE 4}

Distribution of referral source and its relation to obtaining "appropriate services" at the clinic

\begin{tabular}{|c|c|c|c|c|}
\hline & \multicolumn{2}{|c|}{$\begin{array}{l}\text { Study group } \\
\quad N=17^{2}\end{array}$} & \multicolumn{2}{|c|}{$\begin{array}{c}\text { Comparison group } \\
N=111\end{array}$} \\
\hline & $\begin{array}{c}\% \text { Distri- } \\
\text { bution }\end{array}$ & $\begin{array}{c}\% \text { Obtaining } \\
\text { appropriate } \\
\text { services }\end{array}$ & $\begin{array}{c}\% \text { Distri- } \\
\text { bution }\end{array}$ & $\begin{array}{c}\% \text { Obtaining } \\
\text { appropriate } \\
\text { services }\end{array}$ \\
\hline Family Service Society & 19 & 66 & o & o \\
\hline Catholic Social Service & 2 & 100 & 2 & 50 \\
\hline Welfare Department & 19 & 91 & 2 & 100 \\
\hline Courts & 8 & 79 & 3 & 100 \\
\hline Physicians & 5 & 100 & 23 & 96 \\
\hline \multirow{2}{*}{$\begin{array}{l}\text { Psychiatrist-Physician } \\
\text { Self-referred }\end{array}$} & 9 & 87 & 9 & 100 \\
\hline & II & 72 & 11 & 100 \\
\hline Friend or relative & II & 94 & 18 & 85 \\
\hline Psychologists, schools & 4 & 84 & 5 & 80 \\
\hline \multirow{3}{*}{$\begin{array}{l}\text { Hospitals } \\
\text { Other psychiatric clinics } \\
\text { Others: }\end{array}$} & 3 & 100 & 9 & 80 \\
\hline & 3 & 100 & 5 & 100 \\
\hline & 8 & 93 & 14 & 94 \\
\hline \multicolumn{5}{|l|}{ OEO } \\
\hline \multicolumn{5}{|l|}{ Ministers } \\
\hline \multicolumn{5}{|l|}{ Police } \\
\hline \multicolumn{5}{|l|}{ Health Department } \\
\hline \multicolumn{5}{|c|}{ Vocational Rehabilitation } \\
\hline \multicolumn{5}{|c|}{ \% Receiving appropriate service } \\
\hline \multicolumn{2}{|c|}{ For all cases } & 84 & & 91 \\
\hline \multicolumn{5}{|c|}{ For all cases minus Family } \\
\hline Service Society case & $=140)$ & 89 & & 91 \\
\hline
\end{tabular}

The one category of cases in which the percentage of those obtaining appropriate service at the clinic seemed exceptionally out of line was the group from Family Service. Sixty-six per cent of the patients for whom treatment or diagnosis at the clinic was recommended received such services as compared to $84 \%$ of the study group from all referral sources. When this group of patients was removed from the total group, the percentage of the remainder receiving appropriate services rose to $89 \%$. In other words, the group of patients from the Family Service Society lowered the percentages of those 
receiving service significantly below the comparison group. When removed from the study group, figures for study and comparison group in terms of receiving appropriate services became $89 \%$ and $91 \%$. This difference is not significant. It may be concluded that with Family Service cases removed, the proportions of persons in study and comparison groups who receive recommended services are the same.

It may be asked what there is about the referral from Family Service Society which led this group to have a lower percentage of persons receive treatment at the clinic. The number of its clients failing to show up for doctors' assessment is no greater than for the total group. Of the 45 seen by the doctor, 11 or $25 \%$ were referred elsewhere for treatment. This figure is a little higher than the number referred elsewhere from the total group and is related to the fact that many of these patients had been in treatment at the Family Service Society; in the opinion of the doctor, the treatment of 8 of them could well be continued at Family Service rather than be started with a new therapist at the hospital clinic. Of 30 patients for whom treatment at the clinic was recommended, however, only 19 or $63 \%$ began treatment. Although the reasons for this low percentage following through on the doctor's recommendation are not known, this may be due to a combination of: $I$ ) the delay in seeing the doctor; 2) the fact of these patients having had to go through several intake interviews-first with a social worker at the Family Service Society, second with the social worker at the I \& R Service, and third with the doctor at the mental health clinic-before treatment was recommended. This repetition of "initial" interviews may have been a factor in the low proportion carrying out the psychiatrist's recommendation.

These possibilities seem to be supported by the evaluation interviews with Family Service Society workers mentioned earlier. Nearly all the I4 interviewed objected to their clients having to go through another casework interview at the I \& $\mathrm{R}$ Service. As one worker put it, "It is not fair to disturbed people to put them through unnecessary interviews." Fifty per cent of the case workers felt that sending a client to the I \& $R$ Service was less helpful than sending the client to a direct treatment clinic. Nearly half felt the service was too slow. The statistics herein reported appear to confirm their impressions.

It may be concluded from the above findings that the study and comparisons groups are comparable in nearly all instances, with the exception of referral source. The effect of the Family Service Society cases in reducing the percentage obtaining needed treatment at the clinic has been discussed. Other referral source differences are not nearly as great as that from Family Service Society. Some of them may be considered artificially created as a result of various factors; for example, it is felt that the greater visibility of the hospital clinic to doctors working at the hospital resulted in a greater number of referrals by physicians directly to the clinic. It is not considered likely that such artificial differences would greatly affect the outcome. 


\section{DISCUSSION AND CONCLUSIONS}

The main finding of this evaluation was that going through the Intake and Referral Service reduced the probability of a patient's getting into outpatient treatment. This may have been due to the patients having to go to two different places prior to treatment recommendation, or to the time lag between social worker and physician interviews. Since the delay was found to be largely internal, it was believed that changes in office procedures might enable the program to achieve its objective of getting patients prompt and appropriate service at an appropriate place.

The above conclusions apply only to cases sent to the hospital clinic. For the $40 \%$ of the I \& R cases sent elsewhere, one can only speculate in the absence of data. It may well be that these people had treatment expedited for them by the I \& R Service. This may be particularly true for the $17 \%$ of the patients who needed hospitalization.

Since interviews with referring agencies indicated that the program was more useful to workers untrained in evaluating mental problems and unacquainted with resources for helping such clients, and since there was a divergence of opinion concerning the worth of the program to trained workers, it was suggested that program improvements could include the providing of prompt feedback to referring sources and finding means of avoiding duplication of services. Greater effort could be expended, also, in informing all community agencies of the advantages in using the service, especially its potential value in the development of a county-wide register of cases.

The objective of this program was that patients receive "appropriate service." Even where patients entered treatment, effects of therapy were not studied in this evaluation. The same evaluative methods could be applied, it is believed, to determine degree of change in patients following therapy.

It is concluded that the goal attainment model of Deniston et al. can be applied to the evaluation of a mental health program to obtain data bearing on program success. Use of the model for retrospective evaluation has inherent limitations, but these are not sufficiently great that useful information cannot be obtained. More comprehensive application of this method could be arranged by planning for evaluation when programs in mental health are in the developmental stage.

The advent of new mental health centers and programs throughout the country presents program planners with an ideal opportunity to formulate clear and measurable statements of program objectives, subobjectives and activities. The use of comparable areas not yet served by such programs provides an opportunity for rigorous scientific evaluation that may be lost once the federal goal of community mental health programs for all is reached.

\section{REFERENCE}

Deniston, O. L., Rosenstock, I. M., \& Getting, V. A. Evaluation of program effectiveness. Public Health Reports, April 1968, 83, 323. 